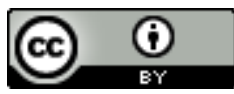

\title{
O DIREITO À EDUCAÇÃO E O ENSINO MÉDIO BRASILEIRO
}

THE RIGHT TO BRAZILIAN EDUCATION AND HIGH SCHOOL

EL DERECHO A LA EDUCACIÓN Y LA ENSEÑANZA SECUNDARIA BRASILEÑA

\section{Tânia Castro Gomes ${ }^{1}$ \\ Maria Lília Imbiriba Sousa Colares ${ }^{2}$}

\begin{abstract}
RESUMO: A educação enquanto direito comum a todos os cidadãos indistintamente incorporada na legislação brasileira a partir de 1946 foi uma conquista após muitas lutas. Conhecer esse passado e refletir sobre o tempo presente, é fundamental para que possamos manter esse direito a todos independente da origem econômica e social. Foi nesta perspectiva que este texto foi elaborado, voltando-se para o ensino médio. Metodologicamente sustenta-se em pesquisa bibliográfica e documental, com base em Romanelli (2010), Frigotto (2006) e Kuenzer (2007) dentre outros; e documentos governamentais. Os resultados apontam que mesmo havendo uma distância significativa entre a elaboração e a implementação efetiva das leis, ocorreram importantes avanços no sentido da universalização do ensino médio. No entanto, ainda existem dificuldades em operacionalizar um ensino cujas finalidades primeiras são o aprimoramento do educando como pessoa humana e a sua preparação para o mercado de trabalho.
\end{abstract}

PALAVRAS-CHAVE: Educação. Ensino médio. Legislação brasileira.

ABSTRACT: The education as a common right to every citizen indistinctly incorporated in the Brazilian legislation from 1946 was a conquest after too much fight. To know this past and reflect about the present time it is fundamental for us to keep this right to everyone independently of its economical and social origin. Was in this perspective that this text was elaborated, turning to High School. Methodologically it sustains in bibliographical and documental research, based in Romanelli (2010), Frigotto (2006) and Kuenzer (2007) among others; and governmental documents. The result shows even with a significant distance between the effective elaboration and implementation of the laws, occurred important advances towards the universalization of the High School. However, still exist difficulties in operationalize an education whose priorities are the improvement of the student as a human person and its preparation for the job market.

KEYWORDS: Education. High school. Brazilian legislation.

RESUMÉN: La educación mientras derecho común a todos los ciudadanos indistintamente incorporada en la legislación brasileña a partir de 1946 fue una conquista después de muchas luchas. Conocer el pasado y reflexionar sobre el tiempo presente, es fundamental para que podamos mantener este derecho a todos independientemente de la origen economica y social. Fue en esta perspectiva este texto fue hecho, volviéndose para la escuela secundaria. Metodológicamente se sostiene en búsqueda bibliográfica y documental, basado en Romanelli (2010) y Kuenzer (2007) entre otros; y documentos gubernamentales. Los resultados señalan que aunque habiendo habido una distancia significativa mientras la elaboración y la implementación efectiva de las leyes, ocurrieron importantes avances en el sentido de la universalización de la escuela secundaria. Sin embargo aún existen dificultades en operacionalizar una enseñanza cuyo las prioridades son el perfeccionamiento del educando como persona humana y su preparación para el mercado de trabajo.

PALABRAS CLAVE: Educación. Escuela secundaria. Legislación brasileña.

Submetido em: 29/08/2017 - Aceito em: 07/02/2018 - Publicado em: 09/02/2017.

\begin{tabular}{l|c|c|c|c|c|c} 
(C) Rev. Educ. Perspec. & Viçosa, $M G$ & v.8 & n.3 & p.363-379 & set./dez. 2017 & eISSN 2178-8359 \\
\hline
\end{tabular}




\section{INTRODUÇÃO}

No que tange as políticas educacionais, não podemos deixar de registrar que é importante contextualizá-las, haja vista que estas perpassam pelos campos histórico, social, econômico e social. Com a Constituição de 1988, ficou estritamente expresso a educação como direito de todos, porém o direito à educação dentro do aspecto histórico foi uma conquista gradativa.

Observamos que aos poucos a educação foi conquistando espaço dentro das constituições federais no decorrer do tempo, que expressam a lei maior, que garante o direito e os deveres dos cidadãos no país. Somente a partir de 1946, a educação é tida como um direito de todos independente da origem econômica e social, e em 1967 torna obrigatório o ensino dos sete aos 14 anos. "A escola se constituía como privilégio de uma pequena parcela da população e era voltada para a formação dos quadros dirigentes da sociedade" (FREITAS; GALTER, 2007, p. 124).

Assim, o referido artigo, dispõe uma síntese do direito à educação em três documentos que orientam a educação brasileira atual: Constituição Federal de 1988 (CF1988), Lei de Diretrizes e Bases da Educação Nacional (LDB Lei Federal no 9.394/96) e o Estatuto da Criança e do Adolescente (ECA Lei $n^{\circ}$ 8.069/90). Além disso, abordamos a trajetória do ensino médio brasileiro na busca de identificar seu objetivo ora propedêutico ora técnico ou ambos. Finalizamos apresentando o Programa Ensino Médio Inovador ProEMI, sua concepção, implementação e documentos norteadores que indicam as ações necessárias à operacionalização do programa consequente da política educacional direcionada ao ensino médio no país.

\section{O DIREITO À EDUCAÇÃO A LUZ DA LEGISLAÇÃO ATUAL}

Com relação a legislação presente, no quadro 1 vamos nos deter especificamente no direito à educação apresentado nos documentos em evidência, CF 1988; LDB 9.394/96 e ECA Lei no 8.069, de 13 de julho de 1990.

Quadro 01. Direito à educação escolar na legislação brasileira atual

\begin{tabular}{|c|c|c|c|c|c|}
\hline $\begin{array}{c}\text { Dispositivo } \\
\text { Legal }\end{array}$ & \multicolumn{2}{|c|}{ Ortigo que dispõe } \\
\hline CF 1988 & \multicolumn{6}{|c|}{ Art. 205} & $\begin{array}{l}\text { A educação, direito de todos e dever do Estado e da família, } \\
\text { será promovida e incentivada com a colaboração da } \\
\text { sociedade, visando ao pleno desenvolvimento da pessoa, seu } \\
\text { preparo para o exercício da cidadania e sua qualificação para } \\
\text { o trabalho. }\end{array}$ \\
\hline LDB - Lei & Art. $1^{\text {o }}$ & A educação abrange os processos formativos que se \\
\hline
\end{tabular}




\begin{tabular}{|c|c|c|}
\hline \multirow[t]{3}{*}{$\begin{array}{c}\text { Federal } n^{\circ} \\
9.394 / 96\end{array}$} & & $\begin{array}{l}\text { desenvolvem na vida familiar, na convivência humana, no } \\
\text { trabalho, nas instituições de ensino e pesquisa, nos } \\
\text { movimentos sociais e organizações da sociedade civil e nas } \\
\text { manifestações culturais. }\end{array}$ \\
\hline & Art. $2^{\circ}$ & $\begin{array}{l}\text { A educação, dever da família e do Estado, inspirada nos } \\
\text { princípios de liberdade e nos ideais de solidariedade } \\
\text { humana, tem por finalidade o pleno desenvolvimento do } \\
\text { educando, seu preparo para o exercício da cidadania e sua } \\
\text { qualificação para o trabalho. }\end{array}$ \\
\hline & Art. $4^{\circ}$ & $\begin{array}{l}\text { O dever do Estado com educação escolar pública será } \\
\text { efetivado mediante a garantia de: } \\
\text { I - educação básica obrigatória e gratuita dos } 4 \text { (quatro) aos } \\
17 \text { (dezessete) anos de idade, organizada da seguinte forma: } \\
\text { a) Pré escola; } \\
\text { b) Ensino fundamental; } \\
\text { c) Ensino Médio; }\end{array}$ \\
\hline \multirow{2}{*}{$\begin{array}{l}\text { ECA LEI No } \\
\text { 8.069, DE } 13 \text { DE } \\
\text { JULHO DE } 1990\end{array}$} & Art. 53. & $\begin{array}{l}\text { A criança e o adolescente têm direito à educação, visando ao } \\
\text { pleno desenvolvimento de sua pessoa, preparo para o } \\
\text { exercício da cidadania e qualificação para o trabalho. }\end{array}$ \\
\hline & Art. 54 & $\begin{array}{l}\text { Garante o atendimento no ensino fundamental e médio } \\
\text { obrigatório e gratuito e reafirma o direito à educação como } \\
\text { direito público e subjetivo. }\end{array}$ \\
\hline
\end{tabular}

Fonte: Elaborado pela autora (2017) a partir dos seguintes documentos: CF (1988), LDB (1996) e ECA (1990).

Os documentos citados no quadro 1, corroboram com esse direito a todos, tanto na universalidade do ensino, quanto no dever do estado, por meio de ações no campo educacional de garantir a operacionalização desse direito financiado pelo poder público.

Vale ressaltar que de acordo com a legislação apresentada, essa garantia do direito à educação perpassa toda a educação básica composta na contemporaneidade pela: educação infantil, ensino fundamental e ensino médio. Em relação ao ensino médio, objeto de estudo em questão, a Lei de Diretrizes e Bases da Educação Nacional (LDB 9.394/96) ratifica e define em seu Artigo 35 o Ensino Médio, antigo $2^{\circ}$ grau, como etapa final da educação básica com duração de três anos que dentre outras finalidades, está a preparação básica para o trabalho e a cidadania do educando.

No entanto, vale retomar de forma breve a memória do ensino médio na construção da história educacional brasileira. Portanto, conforme Romanelli (2010) quanto ao Ato Adicional de 1834 que delegou às províncias brasileiras a responsabilidade do ensino primário e secundário, este ficou sob encargo da iniciativa privada cuja finalidade era a preparação ao ingresso no ensino superior. A Constituição Federal de 1891, incumbiu o Estado de instituir e fiscalizar o ensino primário e profissional. O ensino profissional possuía escola normal para moças e escola técnica para rapazes. Nesse percurso, várias reformas educacionais foram acontecendo no sentido de organizar o ensino brasileiro. Porém, a Reforma Francisco Campos em 1931, após a criação do Ministério da Educação e Saúde

\begin{tabular}{l|c|c|c|c|c|c|} 
(C) Rev. Educ. Perspec. & Viçosa, $M G$ & v.8 & n.3 & p.363-379 & set./dez. 2017 & eISSN 2178-8359 \\
\hline
\end{tabular}


Pública em 1930, estabeleceu com relação ao ensino médio, até então chamado de secundário, contribuições significativas por meio dos decretos $\mathrm{n}^{\circ} 19.890$ de 18 de abril de 1931 e do n $^{\circ} 20.158$ de 30 de junho de 1931, ambos específicos para a organização do ensino secundário, que foi garantido em 1932 pelo decreto $n^{\circ} 21.241$ de 14 de abril de 1932, que consolida as disposições sobre a organização do ensino secundário nos dois decretos anteriores.

Com relação ao ensino secundário antes da reforma, Romanelli afirma que esta estruturou além do ensino secundário, o comercial e o superior, reiterando que:

\begin{abstract}
Até essa época, o ensino secundário não tinha organização digna desse nome, pois não passava, na maior parte do território nacional, de cursos preparatórios, de caráter, portanto, exclusivamente propedêutico. [...] todas as reformas que antecederam o movimento renovador, quando efetuadas pelo poder central, limitaram-se quase exclusivamente ao Distrito Federal, que as apresentava como "modelo" aos Estados, sem, contudo, obrigá-los a adotá-las (ROMANELLI, 2010, p. 133).
\end{abstract}

O Decreto $\mathrm{n}^{\circ} 21.241$ de 14 de abril de 1932 consolidou as disposições sobre a organização do ensino secundário que foi dividido em dois cursos: o primeiro, denominado fundamental, com duração de cinco anos, e após a conclusão desses cinco anos o aluno estaria apto a cursar mais dois anos chamados complementar, em período intensivo, em que teria opção de escolha entre: Jurídico, Medicina, Farmácia, Odontologia, Engenharia ou Arquitetura. A aprovação ao secundário se dava por meio de um exame de admissão que se constituía de prova oral ou escrita. Não podemos deixar de frisar que ao final do decreto, havia uma tabela que continha os valores e taxas referentes a manutenção dos cursos.

No decorrer desse percurso histórico, várias reformas e leis orgânicas foram publicadas no intuito de organizar o sistema de ensino, para adequá-lo a esse sistema e ao momento econômico evidenciado. Ora se buscava um ensino que preparasse para o ingresso em cursos superiores, como somente uma transição a um outro patamar da vida acadêmica, ora se buscava preparar os alunos para o mercado de trabalho exigente de mão de obra.

Em 11 de agosto de 1971 a Lei $n^{\circ} 5.692$, fixa as Diretrizes e Bases para o ensino de $1^{\circ}$ e $2^{\circ}$ graus. Em seu Artigo $1^{\circ}$ explicita seu objetivo geral, que é proporcionar ao educando a formação necessária ao desenvolvimento de suas potencialidades como elemento de autorrealização, qualificação para o trabalho e preparo para o exercício consciente da cidadania. Explicita a preocupação com a formação para o trabalho quando em seu Artigo $4^{\circ}$ no $\S 2^{\circ}$ sugere a preparação para o trabalho por meio da opção no $2^{\circ}$ grau pela habilitação profissional, na qual o aluno de $2^{\circ}$ grau concluía com uma habilitação semiprofissional que o deixava apto para uma profissão no mercado de trabalho.

\begin{tabular}{l|c|c|c|c|c|c} 
(C) Rev. Educ. Perspec. & Viçosa, $M G$ & v.8 & n.3 & p.363-379 & set./dez. 2017 & eISSN 2178-8359 \\
\hline
\end{tabular}


Na sequência, a LDB no 9.394/96, define o ensino médio em seu Art. 35 como final da etapa de educação básica que inicia na educação infantil, continuando no ensino fundamental e fechando o ciclo com o ensino médio. Define também o tempo mínimo de conclusão em três anos. Com relação a finalidade deste artigo, esclarece que,

\begin{abstract}
I - a consolidação e o aprofundamento dos conhecimentos adquiridos no ensino fundamental, possibilitando o prosseguimento de estudos;

II - a preparação básica para o trabalho e a cidadania do educando, para continuar aprendendo, de modo a ser capaz de se adaptar com flexibilidade a novas condições de ocupação ou aperfeiçoamento posteriores;

III - o aprimoramento do educando como pessoa humana, incluindo a formação ética e o desenvolvimento da autonomia intelectual e do pensamento crítico;

IV - a compreensão dos fundamentos científico-tecnológicos dos processos produtivos, relacionando a teoria com a prática, no ensino de cada disciplina (BRASIL, 1996).
\end{abstract}

Ainda no Artigo 36, Seção IV-A a LDB 9394/96 com relação a educação profissional técnica de nível médio, adverte que a educação técnica poderá acontecer sem prejuízo na formação geral no ensino médio, e em ambas a preparação geral para o trabalho e habilitação profissional poderão ocorrer em estabelecimentos do ensino médio ou em parceria com instituições especializadas em educação profissional. No entanto, em 17 de abril de 1997, o então presidente Fernando Henrique Cardoso (1995-1999), sancionou o Decreto $\mathrm{n}^{\circ} 2.208$ que regulamenta o $\S 2^{\circ}$ do art. 36 e os art. 39 a 42 da LDB 9394/96, que estabelece as diretrizes e bases da educação nacional. $\mathrm{O}$ referido decreto, enfatiza a realização da educação profissional como preparação para o mundo do trabalho e forma de ingresso nas atividades produtivas. Ao contrário do que inicialmente a LDB expressava, este divide a educação do ensino médio ressaltando a dualidade de finalidades: um ensino médio propedêutico e um ensino médio técnico semiprofissional. O entendimento de Frigotto (2006, p. 264) nos mostra que,

\footnotetext{
O Brasil é um país econômica e politicamente mais importante da América Latina e o único em que o ensino médio não é obrigatório. Ele constitui uma ausência socialmente construída na sua quantidade e qualidade, o que é o indicador mais claro da opção da formação para o trabalho simples e da não preocupação com as bases da ampliação da produção científica, técnica e tecnológica.
}

Contudo, em 2004, no governo de Luís Inácio Lula da Silva (2003-2007) o Decreto no 5.154 de 23 de julho de 2004, retoma o ensino médio e regulamenta o $\S 2^{\circ}$ do art. 36 e os art. 39 a 41 da LDB 9394/96. Determina em seu art. $4^{\circ}$ que a educação profissional técnica a nível médio deve acontecer vinculada ao ensino médio regular e a forma como acontecerá o ensino: integrada, concomitante e subsequente.

Visando assegurar o atendimento e escola de qualidade que conforme as Diretrizes Curriculares Nacionais para a Educação Básica deve garantir o acesso, permanência e o sucesso no processo ensino aprendizagem e constituição da cidadania (BRASIL, 2013), estratégias foram criadas no sentido de acompanhar e assegurar o desempenho dos alunos na

\begin{tabular}{l|c|c|c|c|c|c} 
() Rev. Educ. Perspec. & Viçosa, $M G$ & v.8 & n.3 & p.363-379 & set./dez. 2017 & eISSN 2178-8359 \\
\hline
\end{tabular}


educação ministrada que considerassem as expectativas declaradas na LDB 9394/96 e nas Diretrizes Curriculares Nacionais para o Ensino Médio (Resolução no 2 de 30 de janeiro de 2012). Em consonância com as Diretrizes Curriculares Nacionais da Educação Básica afirma que,

\begin{abstract}
É expectativa que estas diretrizes possam se constituir num documento orientador dos sistemas de ensino e das escolas e que possam oferecer aos professores indicativos para a estruturação de um currículo do Ensino Médio que atenda as expectativas de uma escola de qualidade que garanta o acesso, a permanência e o sucesso no processo de ensino aprendizagem e constituição de cidadania (BRASIL, 2013, p. 149).
\end{abstract}

Dentre as estratégias de acompanhamento e monitoramento da qualidade de ensino oferecida nas escolas públicas nacionais, a Lei no 9.448 de 14 de março de 1997, transforma o Instituto Nacional de Estudos e Pesquisas Educacionais Anísio Teixeira (INEP) em Autarquia Federal, e dá outras providências. Sobre as ações desenvolvidas pelo INEP na educação, temos o censo e o Exame Nacional de Desempenho de Estudantes (ENADE) no ensino superior, e na educação básica o censo escolar, o Exame Nacional para Certificação de Competências de Jovens e Adultos (ENCCEJA), o Exame Nacional do Ensino Médio (ENEM) para o ensino médio, a Prova Brasil, o Índice de Desenvolvimento da Educação Básica (IDEB) e o Sistema Nacional de Avaliação da Educação Básica (SAEB) ${ }^{\mathrm{i}}$.

De acordo com informações do INEP, o ENEM foi criado em 1998 pelo Ministério da Educação e Cultura (MEC), com vistas a avaliar o desempenho dos alunos ao final da educação básica. Em 2004, o resultado do ENEM passou a ser utilizado como instrumento de seleção para a entrada nas universidades brasileiras. Em 2009, o resultado do desempenho também passou a ser utilizado para a certificação em conclusão do ensino médio. Em 2017, foram anunciadas pelo MEC reformas na aplicação do ENEM, entre outras mudanças, estabeleceu-se que este não certificará mais o ensino médio.

Em 2007 foi criado o IDEB, que representa a iniciativa pioneira de reunir em um só indicador dois conceitos igualmente importantes para a qualidade da educação: fluxo escolar e médias de desempenho nas avaliações. Ele agrega ao enfoque pedagógico dos resultados das avaliações em larga escala do INEP a possibilidade de resultados sintéticos, facilmente assimiláveis, e que permitem traçar metas de qualidade educacional para os sistemas. $\mathrm{O}$ indicador é calculado a partir dos dados sobre aprovação escolar, obtidos no Censo Escolar, e médias de desempenho nas avaliações do INEP, o SAEB - para as unidades da federação e para o país, e a Prova Brasil - para os municípios ii . Ou seja, por meio de um processo de avaliações externas que acontecem na educação básica, aqui nos referimos especificamente ao ensino médio, somente com os alunos do terceiro ano (série final), em um período regular de dois em dois anos, cujo objetivo primeiro era de avaliar a qualidade da educação que está sendo ministrada no país.

\begin{tabular}{l|l|l|l|l|l|l} 
(C) Rev. Educ. Perspec. & Viçosa, $M G$ & v.8 & n.3 & p.363-379 & set./dez. 2017 & eISSN 2178-8359 \\
\hline
\end{tabular}


Outra mudança significativa na trajetória histórica do Ensino Médio foi advinda de uma ruptura política em 2016 na qual a presidente Dilma Vana Roussef em seu segundo mandato (2015-2018) por meio de um impedimento político foi afastada em 31 de agosto de 2016 assumindo imediatamente seu vice Michel Temer que apresentou uma série de reformas e no campo educacional por meio da Medida Provisória 746/2016 propôs a Reforma no Ensino Médio que foi efetivada por meio da Lei $n^{\circ} 13.451$ de 16 de fevereiro de 2017. Entre as principais alterações estão o aumento na carga horária, no currículo, opção de ensino médio regular e técnico e flexibilidade na contratação dos profissionais que atuarão no ensino técnico sem a obrigatoriedade de formação específica.

Deste modo, a história do ensino médio é marcada por uma dualidade caracterizada pela velha escola humanística, que visava formar dirigentes sem, no entanto, permitir o acesso a todos por conta da situação econômica, e escolas que proporcionavam a formação técnicoprofissional visando suprir as necessidades profissionais do mercado produtivo. Em Frigotto (2006, p. 266) atentamos que,

\begin{abstract}
As políticas de educação escolar e de formação técnico-profissional que se consolidaram na hegemonia neoliberal buscaram, não sem contradições, a produção das qualificações necessárias ao funcionamento da economia nos setores restritos que exigem trabalho complexo, o alargamento da formação para o trabalho simples e a formação e quadros para a elaboração e a disseminação da pedagogia da hegemonia.
\end{abstract}

Atualmente, com a mudança científica e tecnológica, a sociedade exige um novo perfil de profissional que se adapte a toda essa mudança. Escolas individualizadas que atendam a públicos de acordo com o interesse e exigências do mercado não satisfazem mais esse mercado, que exigia mão de obra elementar e especializada em diversas atividades profissionais. Em Kuenzer (2007, p. 37) observamos que:

Hoje, para o capital, o "gorila amestrado", não tem função a desempenhar. O capital
precisa, para se ampliar, de trabalhadores capazes de desempenhar sua parte no
acordo social imposto pelas relações de trabalho, pelo cumprimento de seus
deveres, e ao mesmo tempo capazes de incorporar as mudanças tecnológicas, sem
causar estrangulamento a produção. Para tanto, a mera educação profissional já não
é suficiente. Por isso, o próprio capital reconhece que os trabalhadores em geral
precisam ter acesso à cultura sob todas as formas, para o que é indispensável uma
sólida educação básica.

Frigotto (2006) também nos provoca a refletir na possibilidade de ultrapassar a formação técnico profissional adestradora em uma perspectiva dialética, promovendo discussões e debates no sentido de compreender a lógica capitalista partindo da concepção e finalidades da "escola pública, universal, laica, unitária e politécnica ou tecnológica [...] que supere a tradição de adestramento e articule o conhecimento científico e filosófico e trabalho, cultura e vida" (FRIGOTTO, 2006, p. 268). 
Por conseguinte, novas imposições educacionais vão se configurando de acordo com a mudança nas relações produtivas do mercado, e nessas mudanças também vão se desenhando novos requisitos e um novo perfil esperado do aluno do ensino médio, que vai ao longo do curso definir trajetórias onde uma das opções é a de qualificar-se para a entrada ou progressão no mundo do trabalho.

\title{
O PROGRAMA ENSINO MÉDIO INOVADOR
}

Na perspectiva de efetivar as leis e exprimi-las em ações concretas que atendam as demandas sociais, as políticas públicas são elaboradas e executadas visando garantir o acesso a todos os cidadãos. Colares e Colares (2013, p. 86) com relação à política educacional esclarecem que,

\begin{abstract}
A política educacional abrange todos os aspectos relacionados à viabilização deste setor, ou seja, o financiamento, a legislação, a gestão, o currículo, e a avaliação, tanto dos sistemas como um todo, quanto das unidades escolares, em particular. Isto porque as políticas educacionais, mesmo que gestadas nos centros de decisões dos entes federativos (União, Estados, Municípios) podem gerar significativas mudanças nas escolas.
\end{abstract}

Dessa maneira, salientamos que no mandato do presidente Luís Inácio Lula da Silva que correspondeu a dois períodos (01/01/2003 a 01/01/2007 e 01/01/2007 a 01/01/2011), foram assumidos compromissos com a União, Distrito Federal, Estados e Munícipios no sentido de melhorar a qualidade da educação básica no país, dentre os quais citamos o Plano de Desenvolvimento da Educação (PDE), que integra o Plano de Metas Compromisso Todos pela Educação implementado pelo Decreto n ${ }^{\circ} 6.094$ de 24 de abril de 2007. Com 28 diretrizes organizadas sob a forma de metas, estabeleciam-se ações cujo enfoque era o desenvolvimento da educação básica no país. Como mostra Santos (2014, p. 95), “O PDE consiste em um plano educacional de longo alcance, elaborado com base em metas (não cumpridas) do Plano Nacional de Educação (1997-2007)".

$\mathrm{Na}$ intenção de provocar mudanças no interior das escolas públicas mediante ações determinadas pela política educacional, de acordo com o Ministério da Educação, temos dois programas desenvolvidos na educação básica enquanto política pública indutora da educação integral mediante ampliação do tempo escolar: o Programa Mais Educação (PME) e o Programa Ensino Médio Inovador (ProEMI). Com relação ao público atendido, o Programa Mais Educação atende ao Ensino Fundamental, enquanto que o Programa Ensino Médio Inovador aos alunos do Ensino Médio, assim, os alunos da Educação Básica com exceção da Educação Infantiliii, estão contemplados em ações que possibilitam o impulso da educação integral nas instituições escolares. Na busca por desenvolver essa educação, Cavaliere (2012, p. 52) nos adverte que, 


\begin{abstract}
Os modelos de organização para realizar a ampliação do tempo de escola que vem se configurando no País podem ser sintetizados em duas vertentes: uma que tende a investir em mudanças no interior das unidades escolares, de forma que possam oferecer condições compatíveis com a presença de alunos e professores em turno integral, e a outra que tende a articular instituições e projetos da sociedade que ofereçam atividades aos alunos no turno alternativo às aulas, não necessariamente no espaço escolar, mas, preferencialmente, fora dele.
\end{abstract}

Com relação a ações dedicadas ao ensino médio, em abril de 2009, o Ministério da Educação lançou um documento denominado "Ensino Médio Inovador", com bases teóricas que justificavam os indicadores de mudanças alternativas no currículo do ensino médio, com proposições das alterações curriculares, bem como, com o plano de implementação do programa. Em setembro do mesmo ano, a Secretaria de Educação Básica por meio da Coordenação Geral de Ensino Médio elaborou um manual chamado "Programa: Ensino Médio Inovador Documento Orientador", que pretendia nortear as Secretarias Estaduais de Educação e do Distrito Federal, sobre as diretrizes do programa. Nos anos subsequentes os documentos orientadores foram sendo produzidos pelo MEC no intuito de aperfeiçoar a implementação e execução do ProEMI. Os documentos preliminares anunciavam a lei que se segue na intenção de estabelecer uma política educacional voltada ao ensino médio brasileiro.

De acordo com o portal Educação Integral do Ministério da Educação e Cultura ${ }^{\text {iv }}$, o programa Ensino Médio Inovador foi instituído pela Portaria $n^{\circ}$ 971, de 9 de outubro de 2009, no contexto da implementação das ações voltadas ao PDE, fortalecido pelos compromissos assumidos da Declaração de Dakar - Educação para Todos em 2000 . Foi regulamentado pela Resolução $\mathrm{n}^{\mathbf{0}}$ 31, de 22 de julho de 2013, que dispõe sobre a destinação de recursos financeiros às escolas do ensino médio que selecionadas por meio das secretarias de educação aderissem ao desenvolvimento do programa, chegando a indicar inclusive os valores a serem repassados às escolas de acordo com o número de alunos atendidos.

Com relação a criação do programa, a Portaria em seu Artigo $1^{\circ}$, deixa explícito o seu objetivo geral de instituição do programa: apoiar e fortalecer o desenvolvimento de propostas curriculares inovadoras nas escolas do ensino médio não profissional, e no decorrer do documento trata em sua íntegra a essência deste. Em seu artigo $2^{\circ}$ esclarece ainda que o apoio dar-se-á diretamente às Secretarias de Educação e Distrito Federal com vistas a incentivar o ensino científico e humanístico no sentido de melhorar a qualidade da educação no ensino médio não profissionalizante.

Dentre as regras dispostas na Portaria em questão, ressalta que o Programa oportunizará apoio técnico e financeiro por meio da análise, seleção e aprovação de propostas de trabalho apresentadas pelas secretarias de educação que tenham aderido ao Plano de Metas Compromisso Todos pela Educação. A responsabilidade de acompanhar a implementação e monitorar a efetivação do programa nos Estados e Municípios ficará a cargo da Secretaria de 
Educação Básica e a avaliação externa sob incumbência do Instituto Nacional de Estudos e Pesquisas Educacionais Anísio Teixeira.

Quanto a operacionalização e repasse de recursos financeiros do Programa por parte da União assim como dos Estados, foi regulamentado somente no ano de 2013, pela Resolução $\mathbf{n}^{\mathbf{0}} 31$, de 22 de julho de 2013. A referida resolução busca detalhar as bases em que o programa será desenvolvido iniciando com as justificativas para o funcionamento deste, dentre as quais, a necessidade de partilhar a intenção de melhorar o ensino médio com os entes federados, principalmente, por ações que propiciem novas organizações curriculares. Segue-se os critérios de seleção para a participação das escolas e as opções de ações contempladas denominadas Projeto de Redesenho Curricular (PRC), para a escolha a ser realizada pela comunidade escolar.

O ProEMI que integra as ações do Plano de Desenvolvimento da Educação é concebido como estratégia do Governo Federal para induzir a reestruturação dos currículos do Ensino Médio, compreendendo que as ações propostas inicialmente vão sendo incorporadas ao currículo das escolas, ampliando o tempo na escola e a diversidade de práticas pedagógicas, atendendo às necessidades e expectativas dos estudantes do ensino médio (BRASIL, 2012).

A reestruturação no currículo das escolas, é realizada por meio do PRC, a ser elaborado pela comunidade escolar de acordo com a realidade apontada por meio de um diagnóstico prévio, com atividades inovadoras que estejam em consonância com as orientações previstas nas Diretrizes Curriculares Nacionais para o Ensino Médio. Essas ações comporão o currículo e podem ser ofertados nos formatos de disciplinas optativas, oficinas, clubes de interesse, seminários integrados, grupos de pesquisa, trabalhos de campo e demais ações que se proponham interdisciplinares. As ações são organizadas em macrocampos nos quais três são obrigatórios: o acompanhamento pedagógico, leitura e letramento, e iniciação científica e pesquisa. Além dos obrigatórios, a escola pode fazer opção no mínimo por mais dois, para que seja totalizado cinco macrocampos de ações. Os macrocampos sugeridos pelo programa são: acompanhamento pedagógico (Linguagem Matemática, Ciências Humanas e Ciências da Natureza); iniciação científica e pesquisa; leitura e letramento; línguas estrangeiras; cultura corporal; produção e fruição das artes; comunicação, cultura digital e uso de mídias e participação estudantil.

Assim, percebemos a preocupação e o interesse do governo federal em tornar o ensino médio mais atrativo para o atendimento aos adolescentes e jovens, com atividades interdisciplinares que estimulem e promovam práticas indutoras de educação integral nesse nível de ensino. Essa possibilidade opcional das escolas em alterar e reorganizar as atividades curriculares nos três anos que correspondem ao ensino médio, vem ao encontro da meta $03^{\mathrm{vi}}$, acordada no documento Educação para Todos que se compromete em assegurar que as necessidades de

\begin{tabular}{l|c|c|c|c|c|c} 
(C) Rev. Educ. Perspec. & Viçosa, $M G$ & v.8 & n.3 & p.363-379 & set./dez. 2017 & eISSN 2178-8359 \\
\hline
\end{tabular}


aprendizagem de todos os jovens e adultos sejam atendidas pelo acesso equitativo à aprendizagem apropriada, às habilidades para a vida e à programas de formação para a cidadania.

Em relação aos resultados esperados e apresentados pelo IDEB $^{\text {vii }}$ atentamos para o fato de que os resultados no Ensino Médio nos anos de 2007 a 2015 não conseguiram alcançar os índices projetados, considerando as informações apresentadas resultantes de uma média aritmética dos estados brasileiros e de acordo com os próprios critérios do Instituto Nacional de Estudos e Pesquisas Educacionais Anísio Teixeira, incluindo as dependências estaduais, públicas e privadas. Vale ressaltar ainda, que os números relacionados ao aproveitamento escolar no ensino médio aferidos pelo IDEB não são individuais por escola, estes são analisados por amostragem em que as escolas participantes são definidas de modo aleatório pelo INEP e submetem turmas de $3^{\circ}$ ano do ensino médio à avaliação aplicada. Quando nos referimos aos dados individuais nos reportamos ao rendimento escolar de cada unidade de ensino.

Tabela 1: IDEB referente ao $3^{\circ}$ Ano do Ensino Médio no Brasil - Metas projetadas e observadas de 2005 a 2015

\begin{tabular}{cccccccc}
\hline Anos & $\mathbf{2 0 0 5}$ & $\mathbf{2 0 0 7}$ & $\mathbf{2 0 0 9}$ & $\mathbf{2 0 1 1}$ & $\mathbf{2 0 1 3}$ & $\mathbf{2 0 1 5}$ & $\mathbf{2 0 2 1}$ \\
\hline Metas projetadas & --- & $\mathbf{3 . 1}$ & $\mathbf{3 . 2}$ & $\mathbf{3 . 4}$ & 3.6 & 4.0 & 4.9 \\
IDEB observado (resultados & 3.1 & $\mathbf{3 . 2}$ & $\mathbf{3 . 4}$ & $\mathbf{3 . 4}$ & 3.4 & 3.5 & -- \\
das escolas) & & & & & & & \\
\hline
\end{tabular}

Fonte: INEP, 2016.

Notamos na tabela 1 que nos anos de 2011 e 2013 em que as escolas públicas foram avaliadas, os resultados sobre o desempenho dos alunos no ensino médio divulgados em 2012 e 2014 respectivamente, não foram satisfatórios em consonância com o que preconiza as Diretrizes Curriculares Nacionais da Educação Básica, oriundas da necessidade da organização da educação nacional quanto a princípios, fundamentos e procedimentos diante de diversas mudanças ocorridas na educação básica, quando se refere ao Ensino Médio.

Estas Diretrizes orientam-se no sentido do oferecimento de uma formação humana integral, evitando a orientação limitada da preparação para o vestibular e patrocinando um sonho de futuro para todos os estudantes do Ensino Médio. Esta orientação visa à construção de um Ensino Médio que apresente uma unidade e que possa atender a diversidade mediante o oferecimento de diferentes formas de organização curricular, o fortalecimento do projeto político pedagógico e a criação das condições para a necessária discussão sobre a organização do trabalho pedagógico (BRASIL, 2013, p. 155). 
Diante do que se espera do ensino médio e dos resultados apresentados, nos anos em que houve acompanhamento por meio do IDEB dos índices produzidos, foi encaminhada pelo governo federal ao Congresso Nacional, uma proposta de reforma no ensino médio por meio da Medida Provisória MP 746/2016 em 22 de setembro de 2016, que instituiu a Política de Fomento à implementação de Escolas de Ensino Médio em Tempo Integral, alterando a Lei n 9.394, de 20 de dezembro de 1996, que estabelece as Diretrizes e Bases da Educação Nacional (LDB), e a Lei $n^{\circ} 11.494$ de 20 de junho 2007, que regulamenta o Fundo de Manutenção e Desenvolvimento da Educação Básica e de Valorização dos Profissionais da Educação (FUNDEB), e dá outras providências.

A medida provisória propõe a reestruturação de toda a estrutura de aprendizagem dentre as quais mencionamos - mudanças na reestruturação no ensino médio de acordo com a MP 746/2016 como: 1) A ampliação progressiva da carga horária de oitocentas para mil e quatrocentas horas; 2) Componentes curriculares que hoje estão presentes no ensino médio, tornam-se obrigatórios somente na educação infantil e no ensino fundamental como, por exemplo, o ensino da arte e educação física, facultados no ensino médio assim como a filosofia e a sociologia; 3) O conteúdo deverá ser composto pelas disciplinas de língua portuguesa, matemática, ciências da natureza, ciências humanas e formação técnica e profissional, obrigatórios nos três anos de curso; 4) $\mathrm{O}$ aluno tem a possibilidade de escolha quanto a sua formação no ensino médio: formação tradicional ou formação técnica. Porém, a MP 746/2016 deixa nítido em seu Art. 36 que a escolha dos itinerários formativos específicos fica condicionado a oferta nos sistemas de ensino; 5) Com relação aos profissionais que atuarão no ensino médio, a reforma permite que sejam contratados profissionais sem diploma técnico ou superior, porém com a comprovação de notório saber na área de atuação; 6) Incentiva financeiramente as escolas de ensino médio a atuarem como escolas de tempo integral.

Com base neste documento, no que se refere à política de fomento à implementação de escolas de ensino médio em tempo integral esta foi regulamentada pela Resolução $\mathrm{n}^{\circ} 4$, de 25 de outubro de 2016, que destina recursos financeiros, nos moldes operacionais e regulamentares do Programa Dinheiro Direto na Escola (PDDE), a escolas públicas estaduais e do Distrito Federal a fim de apoiar e fortalecer o desenvolvimento de propostas curriculares inovadoras, em conformidade com o Programa Ensino Médio Inovador.

Diante desse novo cenário de reformas na política educacional no Brasil em 2016, dentre os programas indutores da política de educação integral destinados ao público do ensino fundamental e médio, respectivamente, continuam o Programa Mais Educação e o Programa Ensino Médio Inovador, porém, atualmente com mudanças em suas configurações incluindo a nomenclatura em que estes passam a chamar-se: Programa Novo Mais Educação e Programa Ensino Médio Inovador (EMI).

\begin{tabular}{l|c|c|c|c|c|c} 
() Rev. Educ. Perspec. & Viçosa, $M G$ & v.8 & n.3 & p.363-379 & set./dez. 2017 & eISSN 2178-8359 \\
\hline
\end{tabular}


A edição atual do Programa está alinhada às diretrizes e metas do Plano Nacional de Educação (PNE) 2014-2024 e à reforma do Ensino Médio proposta pela Medida Provisória n ${ }^{\circ}$ 746/2016 regulamentada pela Resolução do Fundo Nacional de Desenvolvimento da Educação (FNDE) no 4 de 25 de outubro de 2016. Assim, enquanto objetivo da nova proposta do programa EMI, temos o apoio e fortalecimento dos Sistemas de Ensino Estaduais e Distrital no desenvolvimento de propostas curriculares inovadoras nas escolas de Ensino Médio, disponibilizando apoio técnico e financeiro, consoante à disseminação da cultura de um currículo dinâmico, flexível, que atenda às expectativas e necessidades dos estudantes e às demandas da sociedade atual.

A adesão ao Ensino Médio Inovador é realizada pelas Secretarias de Educação Estaduais e Distrital, que selecionam as escolas de Ensino Médio que participarão do programa EMI. Essas escolas receberão apoio técnico e financeiro por meio do Programa Dinheiro Direto na Escola para a elaboração e o desenvolvimento de suas Propostas de Redesenho Curricular. As PRC deverão estar alinhadas com os projetos político pedagógicos das escolas, articulando as dimensões do trabalho, da ciência, da cultura e da tecnologia, de acordo com as Diretrizes Curriculares Nacionais para o Ensino Médio (Resolução CEB/CNE nº. 2, de 30 de janeiro de 2012).

\section{CONSIDERAÇÕES FINAIS}

$\mathrm{Na}$ legislação nacional utilizada nas reflexões no decorrer do trabalho, notamos que existe uma evolução na conquista da educação acessível a todas as pessoas, independente de classe social. Dentro dessa lógica, reiteramos também que esse ensino universalizado deva conduzir a formação do educando com base em três pilares fundamentais: desenvolvimento pleno da pessoa, preparo do cidadão em exercer seus direitos fundamentais e preparação para o mercado de trabalho.

Outra questão diz respeito a manifestação das finalidades do ensino médio que nos mostra que dentre seus objetivos, mesmo na segunda etapa da educação básica, continua sendo o aprimoramento do educando como pessoa humana, a preparação para o mercado de trabalho incluindo a formação ética e o desenvolvimento da autonomia intelectual e do pensamento crítico, bem como, a compreensão dos processos produtivos na intenção de aproximar teoria e prática.

Atentamos também para o novo Programa Ensino Médio Inovador como política indutora de educação integral e a nova lei do ensino médio que sinaliza uma reestruturação teórica em toda sua organização que provoca críticas quanto a sua efetiva implementação; as condições estruturais das escolas que ofertam o ensino médio; a opção de escolha pelos jovens em

\begin{tabular}{l|c|c|c|c|c|c} 
(C) Rev. Educ. Perspec. & Viçosa, $M G$ & v.8 & n.3 & p.363-379 & set./dez. 2017 & eISSN 2178-8359 \\
\hline
\end{tabular}


cursar ensino médio técnico ou propedêutico; valorização dos profissionais que atuarão na nova proposta; a não obrigatoriedade de algumas disciplinas mesmo constando no currículo; o aumento progressivo da carga horária que induz a educação em tempo integral como possibilidade; bem como, a adesão a essa forma de educação somente pelo repasse diferenciado de recursos financeiros sem, no entanto, priorizar a questão pedagógica.

No caminho percorrido, notamos a frequente dúvida quanto aos objetivos do ensino médio que são instituídos de acordo com a ordem econômica, por vezes, temos um ensino médio que prepara para outros patamares como o ensino superior, outrora percebemos uma urgência em formar os jovens para o mercado de trabalho, oferecendo um ensino técnico com expectativas de inserção imediata no mercado profissional.

\section{REFERÊNCIAS}

BRASIL. Diretrizes Curriculares Nacionais Gerais da Educação Básica. Ministério da Educação. Secretaria de Educação Básica. Diretoria de Currículos e Educação Integral. Brasília: MEC, SEB, DICEI, 2013.

BRASIL. Educação Integral/PROEMI. Ministério da Educação e Cultura/MEC. Disponível em: <http://educacaointegral.mec.gov.br/proemi> Acesso em: 23 nov. 2016.

BRASIL. Ensino Médio Inovador. Ministério da Educação e Cultura/MEC. Disponível em: <http://portal.mec.gov.br/dmdocuments/ensino_medioinovador.pdf.> Acesso em: 23 nov. 2016.

BRASIL. Estatuto da Criança e do Adolescente - ECA. Lei Federal no 8.069, de 13 de julho de 1990. Dispõe sobre o Estatuto da Criança e do Adolescente e dá outras providências. Disponível em: <https://www.planalto.gov.br/ccivil_03/leis/L8069.htm>. Acesso em: 21 nov. 2016

BRASIL. Instituto Nacional de Estudos e Pesquisas Educacionais Anísio Teixeira- INEP. IDEB - Resultados e Metas. Disponível em:

<http://ideb.inep.gov.br/resultado/resultado/resultadoBrasil.seam?cid=3196067> Acesso em: 23 nov. 2016

BRASIL. Instituto Nacional de Estudos e Pesquisas Educacionais Anísio Teixeira INEP. Disponível em: <http://portal.inep.gov.br//>. Acesso em: 05 abr. 2017.

BRASIL. Instituto Nacional de Estudos e Pesquisas Educacionais Anísio Teixeira - INEP. Base Jurídica. Disponível em: <http://portal.inep.gov.br//>. Acesso em: 05 abr. 2017. 
BRASIL. Lei de Diretrizes e Bases da Educação Nacional/LDB. Lei no 9394, de 20 de dezembro de 1996 que estabelece as diretrizes e bases da educação nacional. Disponível em: <https://www.planalto.gov.br/ccivil_03/Leis/L9394.htm> Acesso em: 21 nov. 2016.

BRASIL. Medida Provisória no 746, de 22 de setembro de 2016. Disponível em: <https://www.planalto.gov.br/ccivil_03/_Ato2015-2018/2016/Mpv/mpv746.htm>. Acesso em: 23 nov. 2016.

BRASIL. Ministério da Educação e Cultura. Portaria no 971, de 09 de outubro de 2009. Disponível em: <http://portal.mec.gov.br/docman/documentos-pdf/1634-port-971/file //>. Acesso em: 01 maio 2016.

BRASIL. Ministério da Educação e Cultura. Resolução no 31, de 22 de julho de 2013. Disponível em: <https://goo.gl/GPCfdt>. Acesso em: 01 maio 2016.

BRASIL. Ministério da Educação e Cultura/MEC. Ações e Programas da Educação Básica. Disponível em: <http//: portal.mec.gov.br〉. Acesso em: 21 nov. 2016.

BRASIL. Ministério da Educação e Cultura/MEC. Diário Oficial da União - Seção 1. Portaria $n^{0}$ 971, de 09 de outubro de 2009. Disponível em: <http://pactoensinomedio.mec.gov.br/images/pdf/port_971_09102009.pdf>. Acesso em: 23 nov. 2016.

BRASIL. O Programa Nacional de Acesso ao Ensino Técnico e Emprego PRONATEC. Disponível em: <http://portal.mec.gov.br〉. Acesso em: 16 abr. 2017.

BRASIL. PDE Escola. Plano de Desenvolvimento da Escola - PDE Interativo. Disponível em: <http://pdeescola.mec.gov.br/index.php/pde-interativo>. Acesso em: 14 abr. 2017.

BRASIL. Plano de Desenvolvimento da Educação (PDE) - Razões, Princípios e Programas, 2007.

BRASIL. Plano Nacional de Educação (2001-2011). Lei n ${ }^{\circ} 010172$, de 9 de janeiro de 2001. Aprova o Plano Nacional de Educação e dá outras providências. Disponível em: <http://portal.mec.gov.br/arquivos/pdf/L10172.pdf>. Acesso em: 21 nov. 2016.

BRASIL. Programa Ensino Médio Inovador - Documento Orientador. Ministério da Educação e Cultura/MEC Disponível em:

<http://portal.mec.gov.br/dmdocuments/documento_orientador.pdf.>. Acesso em: 23 nov. 2016.

BRASIL. Resolução no 4, de 25 de outubro de 2016. Disponível em: <https://goo.gl/QaSJf9> Acesso em: 23 nov. 2016.

BRASIL. Secretaria de Ensino Fundamental I, Ministério da Educação e Desporto, 2003.

\begin{tabular}{l|c|c|c|c|c|c} 
(C) Rev. Educ. Perspec. & Viçosa, $M G$ & v.8 & n.3 & p.363-379 & set./dez. 2017 & eISSN 2178-8359 \\
\hline
\end{tabular}


BRASIL. Ministério da Educação e Cultura - MEC. Ações e Programas da Educação Básica. Disponível em: <http://portal.mec.gov.br/secretaria-de-educacao-basica/programas-eacoes.> Acesso em: 10 abr. 2016.

BRASIL. Ministério da Educação e Cultura - ProEMI. Disponível em:

<http://portal.mec.gov.br/ensino-medio-inovador/documento//.> Acesso em: 05 jun. 2016.

BRASIL. Presidência da República. Constituição da República Federal do Brasil de 1988. Brasília, 1988. Disponível em: <http //planalto.gov.br/civil_03/Constituição\%C3A7ao.htm>. Acesso em: 10 maio 2016.

COLARES, Anselmo Alencar; COLARES, Maria Lília Imbiriba Sousa. As políticas educacionais e a formação de professores. In: JEFFREY, Debora Cristina; AGUILAR, Luis Enrique. Balanço da política Educacional Brasileira (1999-2009): ações e programas. 1. ed. Campinas, SP: Mercado das Letras, 2013.

FREITAS, Cezar Ricardo de; GALTER, Maria Inalva. Reflexões sobre a Educação Integral no decorrer do Século XX. Revista de Educação Educere et Educare, v. 1. n. 3, p. 123-138, jan./jul. 2007.

KUENZER, Acácia Zeneida. Ensino Médio e profissional: as políticas do Estado neoliberal. 4 ed. São Paulo: Cortez, 2007.

LIMA, Júlio César França; NEVES, Lúcia Maria Wanderley. (Org.) Fundamentos da Educação Escolar do Brasil Contemporâneo. Rio de Janeiro: Editora Fiocruz/EPSJV, 2006. 320 p.

ROMANELLI, Otaíze de Oliveira. História da Educação no Brasil (1930-1973). 36. ed. Petrópolis, RJ: Vozes, 2010.

SANTOS, Pablo Silva Machado Bispo dos. Guia Prático da Política Educacional no Brasil: Ações, planos, programas e impactos. 2. ed. rev. e ampl. São Paulo: Cengage Lerning, 2014. 


\section{NOTAS}

${ }^{\mathrm{i}}$ Informações disponíveis em: <http://portal.inep.gov.br>. Acesso em: 05 abr. 2017.

ii Informações disponíveis em: <http://portal.inep.gov.br>. Acesso em: 05 jun. 2016.

iii $\mathrm{O}$ atendimento já está normatizado para jornada parcial de quatro horas ou integral de sete horas com proposta pedagógica diferenciada em virtude do público atendido. Ver LDB 9394/1996 e Diretrizes Curriculares Nacionais para a Educação Infantil (2010).

${ }^{\text {iv }}$ Informações disponíveis em: <http://educacaointegral.mec.gov.br/proemi〉. Acesso em: 23 nov. 2016.

v A Educação para Todos (EPT) é um compromisso global firmado por 164 governos reunidos na Cúpula Mundial de Educação, em Dakar (2000), para oferecer a todas as crianças, jovens e adultos uma educação que satisfaça suas necessidades básicas de aprendizagem, no melhor e mais pleno sentido do termo, e que inclua aprender a aprender, a fazer, a conviver e a ser. O compromisso estabeleceu-se por meio de seis metas a serem alcançadas até 2015. Disponível em: 〈http://educacaosec21.org.br〉. Acesso em: 29 jan. 2017.

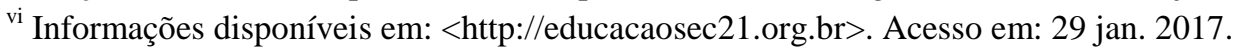

vii Indicador avaliativo que reúne dois critérios como indicador de qualidade na educação: fluxo escolar e média no desempenho das avaliações aplicadas. O indicador é calculado a partir dos dados sobre aprovação escolar, obtidos no Censo Escolar e médias de desempenho nas avaliações do INEP: o SAEB para as unidades de federação e para o país e a Prova Brasil para os municípios. Disponível em: <http://ideb.inep.gov.br〉. Acesso em: 23 nov. 2016.

\section{Sobre as Autoras}

Tânia Castro Gomes: Mestranda em Educação do Programa de Pós-graduação em Educação da Universidade Federal do Oeste do Pará. E-mail: tcastrogomes@bol.com.br

Maria Lília Imbiriba Sousa Colares: Doutora e Pós-doutora em Educação pela Universidade Estadual de Campinas. Docente do Programa de Pós-graduação em Educação da Universidade Federal do Oeste do Pará. E-mail: lilia.colares@ hotmail.com 